Figure 4S. Ramachandran plot containing the $15 \alpha$, L-glutamate residues of the polypeptide chain for the $6 \mathrm{~ns}$ trajectory at $300 \mathrm{~K}$. Dihedral angles were defined as is usual in polypeptides: $\varphi=\mathrm{C}-\mathrm{N}-\mathrm{C}^{\alpha}-\mathrm{C}$ and $\psi=\mathrm{N}-\mathrm{C}^{\alpha}-\mathrm{C}-\mathrm{N}$.

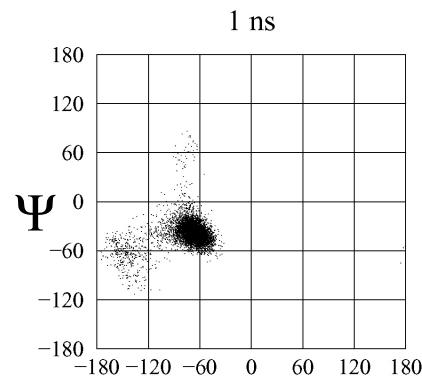

$\varphi$

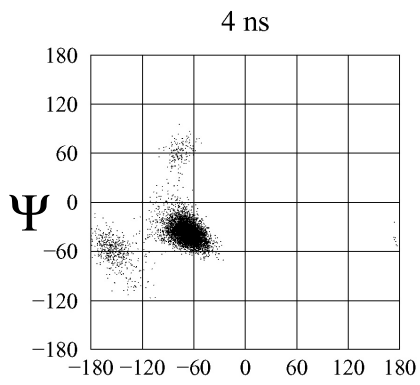

$\varphi$

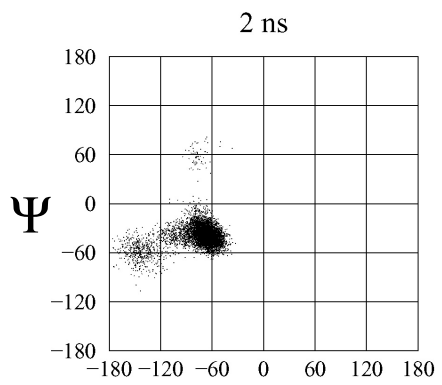

$\varphi$

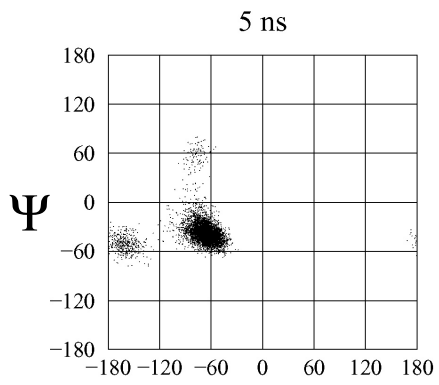

$\varphi$

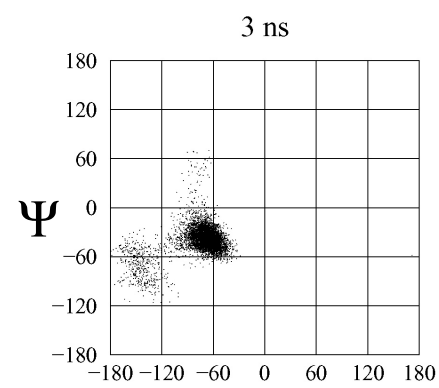

$\varphi$

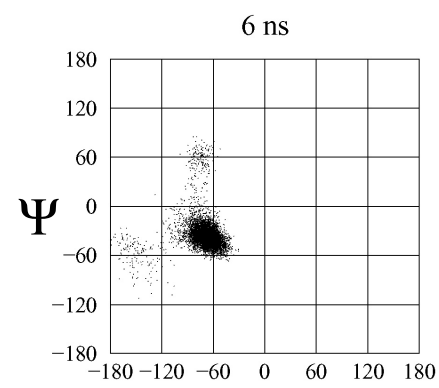

$\varphi$ 
Figure 5S. Ramachandran plot containing the $15 \alpha$,L-glutamate residues of the polypeptide chain for the $6 \mathrm{~ns}$ trajectory at $350 \mathrm{~K}$. Dihedral angles were defined as is usual in polypeptides: $\varphi=\mathrm{C}-\mathrm{N}-\mathrm{C}^{\alpha}-\mathrm{C}$ and $\psi=\mathrm{N}-\mathrm{C}^{\alpha}-\mathrm{C}-\mathrm{N}$.
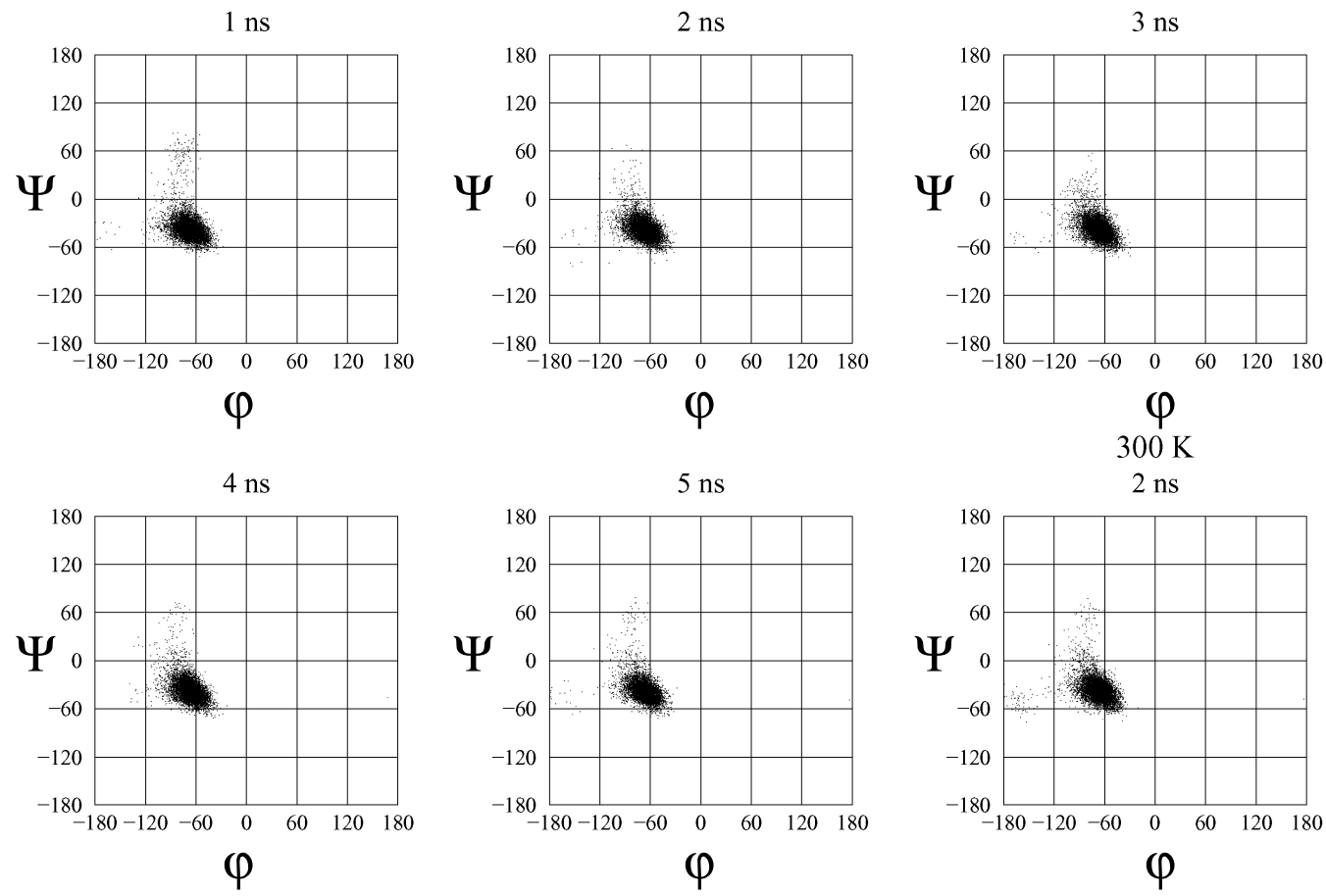
Figure 6S. Ramachandran plot containing the $15 \alpha$, L-glutamate residues of the polypeptide chain for the $6 \mathrm{~ns}$ trajectory at $400 \mathrm{~K}$. Dihedral angles were defined as is usual in polypeptides: $\varphi=\mathrm{C}-\mathrm{N}-\mathrm{C}^{\alpha}-\mathrm{C}$ and $\psi=\mathrm{N}-\mathrm{C}^{\alpha}-\mathrm{C}-\mathrm{N}$.
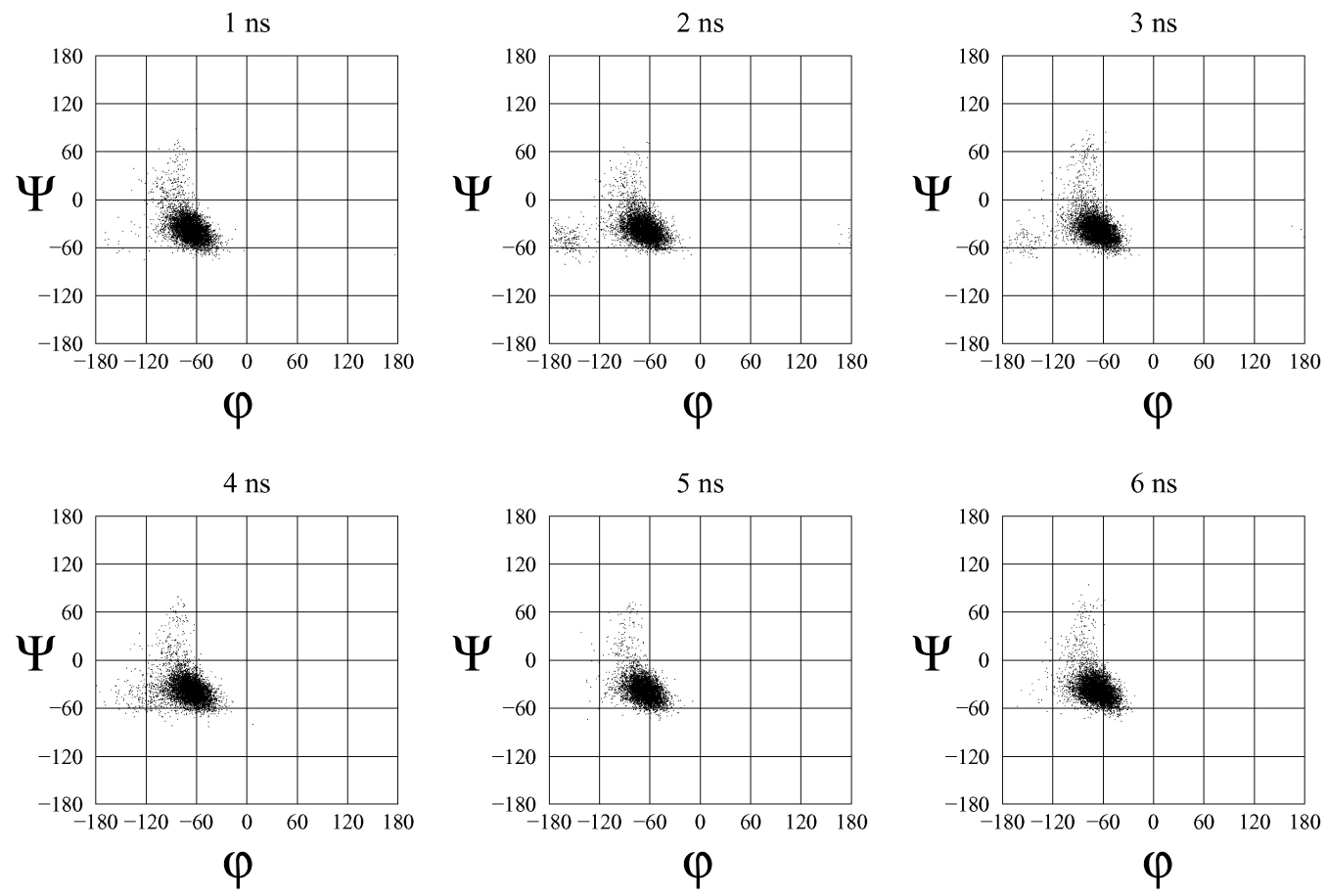
Figure7S. Ramachandran plot containing the $15 \alpha$, L-glutamate residues of the polypeptide chain for the two independent $6 \mathrm{~ns}$ trajectories at $450 \mathrm{~K}$. Dihedral angles were defined as is usual in polypeptides: $\varphi=\mathrm{C}-\mathrm{N}-\mathrm{C}^{\alpha}-\mathrm{C}$ and $\psi=\mathrm{N}-\mathrm{C}^{\alpha}-\mathrm{C}-\mathrm{N}$.

\section{SIMULATION 1}
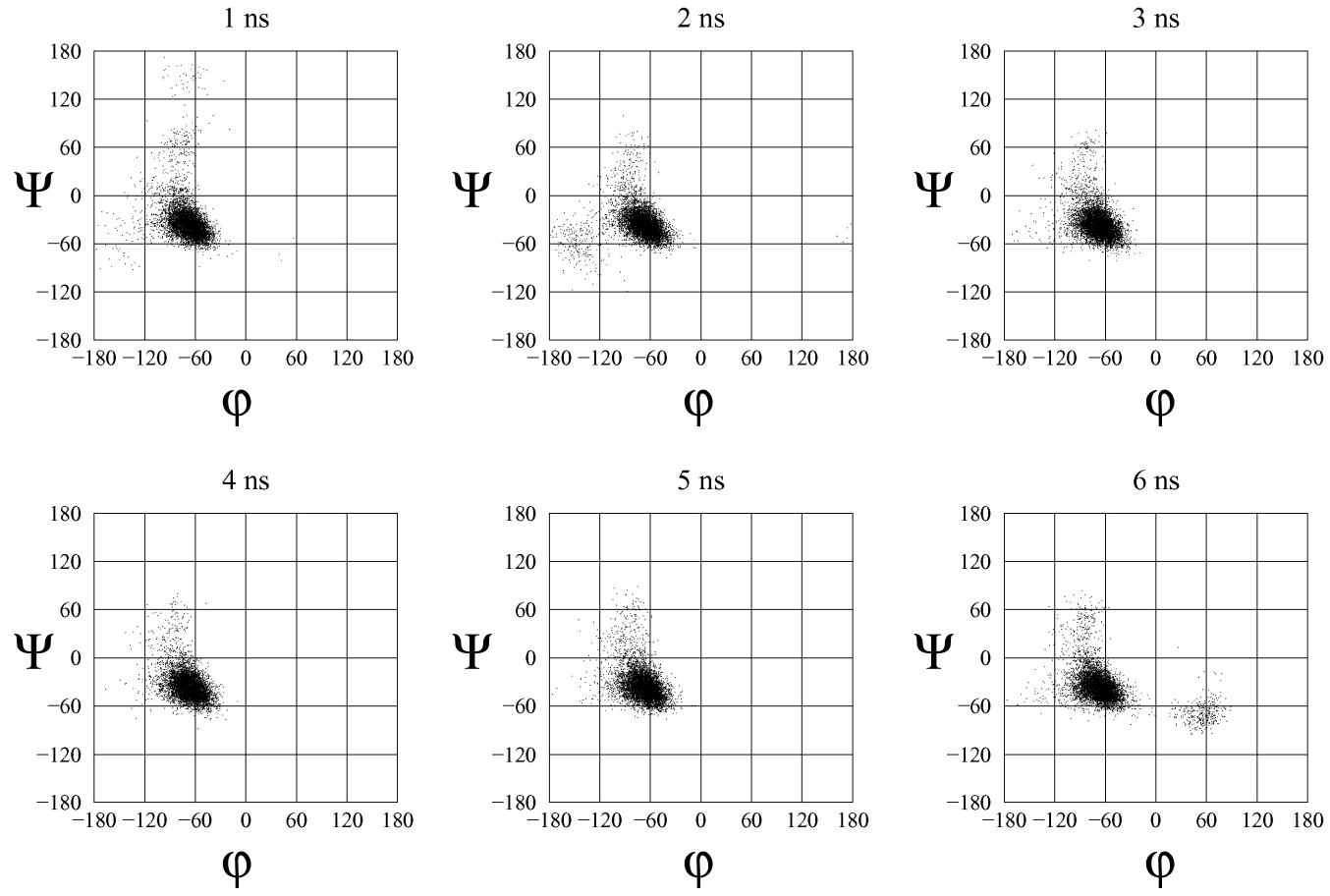

\section{SIMULATION 2}
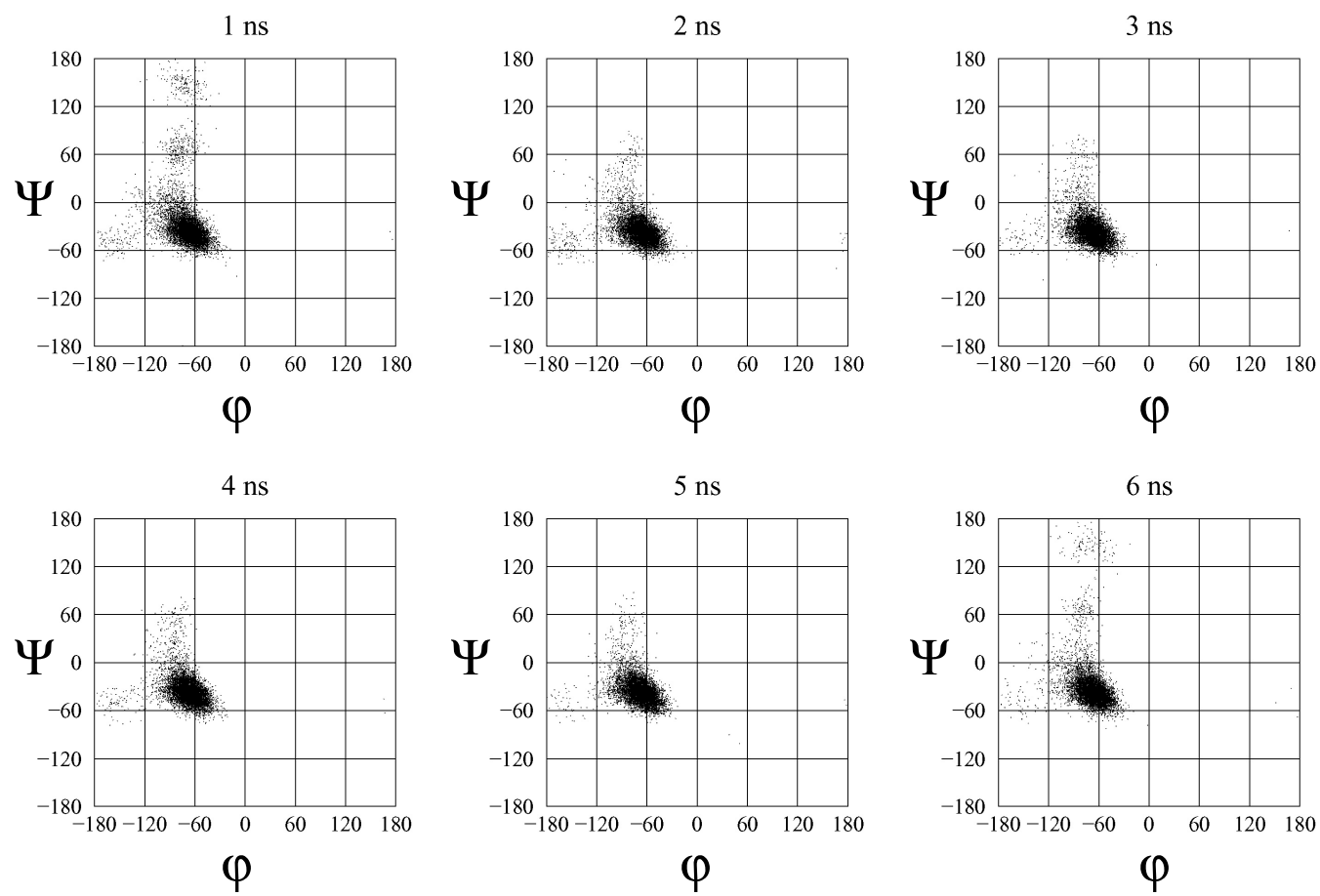
Figure8S. Ramachandran plot containing the $15 \alpha$, L-glutamate residues of the polypeptide chain for the two independent 12 and $6 \mathrm{~ns}$ trajectories at $500 \mathrm{~K}$. Dihedral angles were defined as is usual in polypeptides: $\varphi=C-N-C^{\alpha}-C$ and $\psi=N-C^{\alpha}-C-N$.

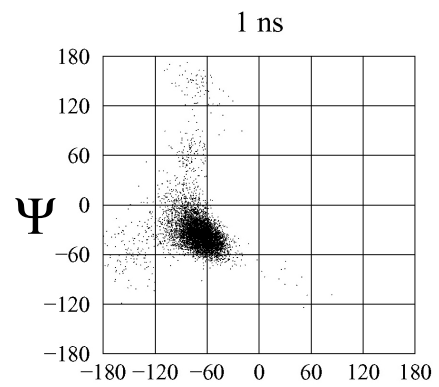

$\varphi$

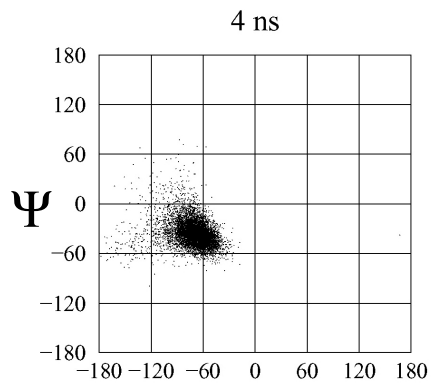

$\varphi$
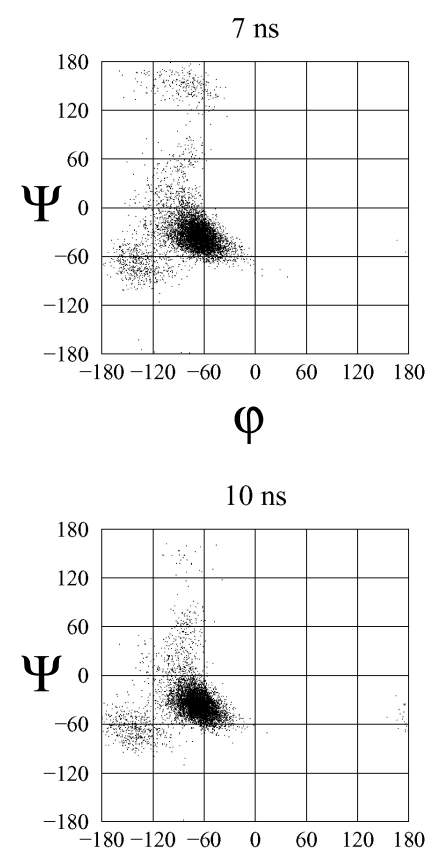

$\varphi$

\section{SIMULATION 1}

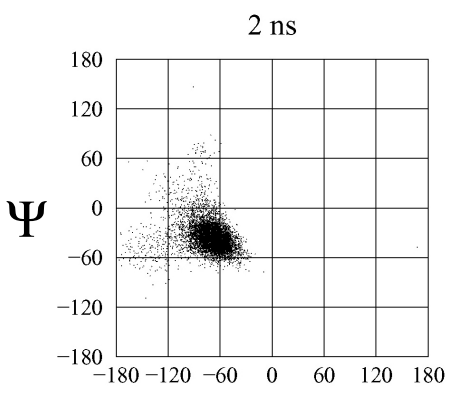

$\varphi$
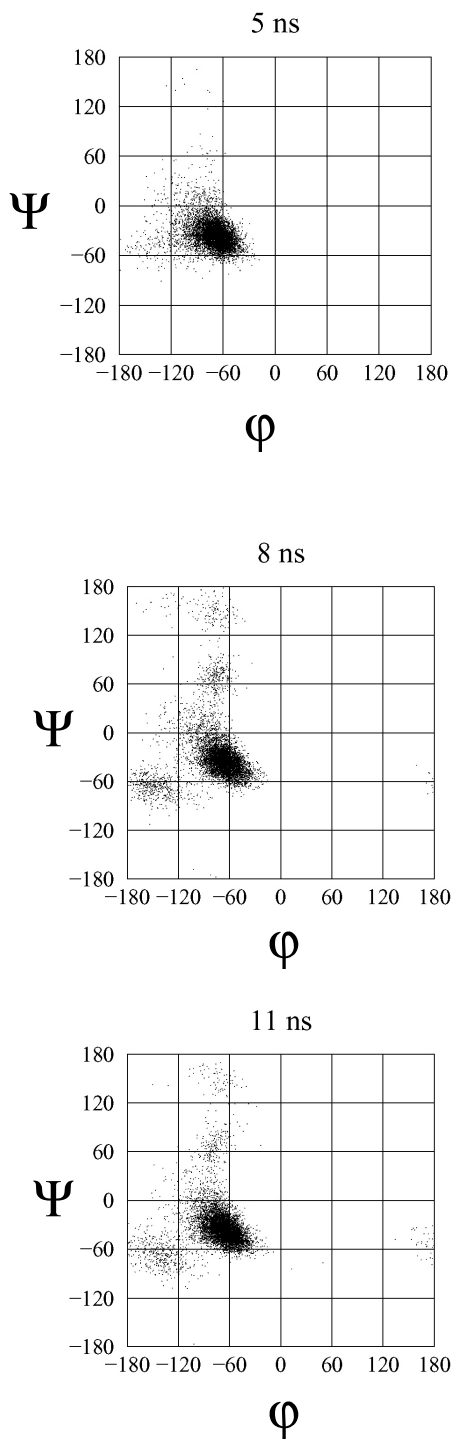

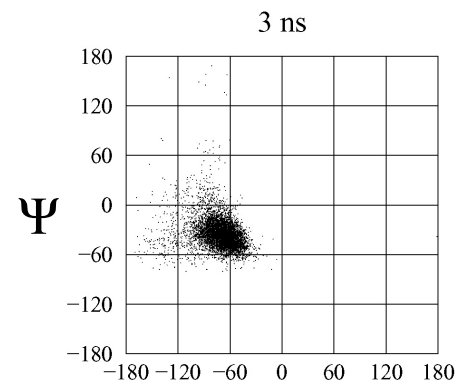

$\varphi$

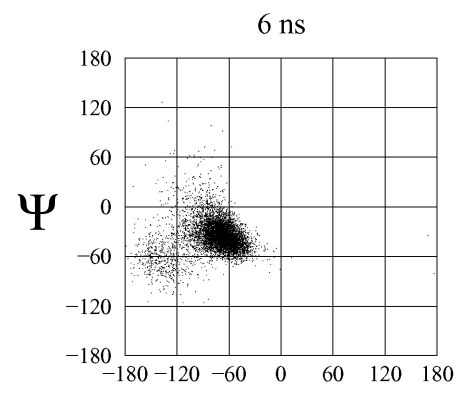

$\varphi$
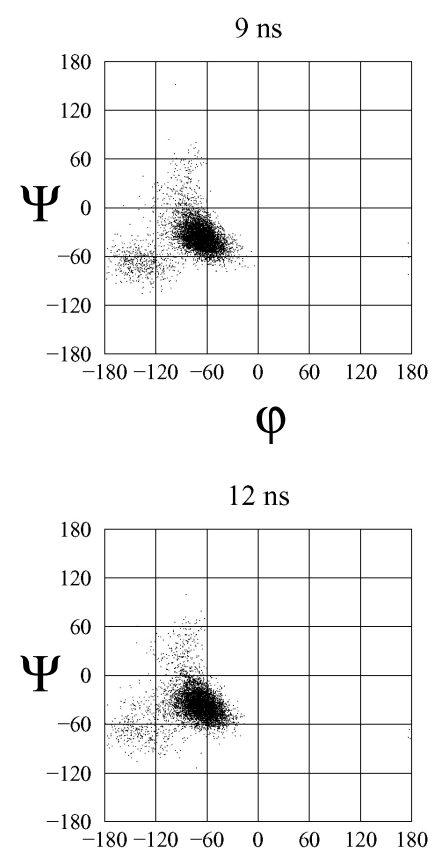

$\varphi$ 
SIMULATION 2
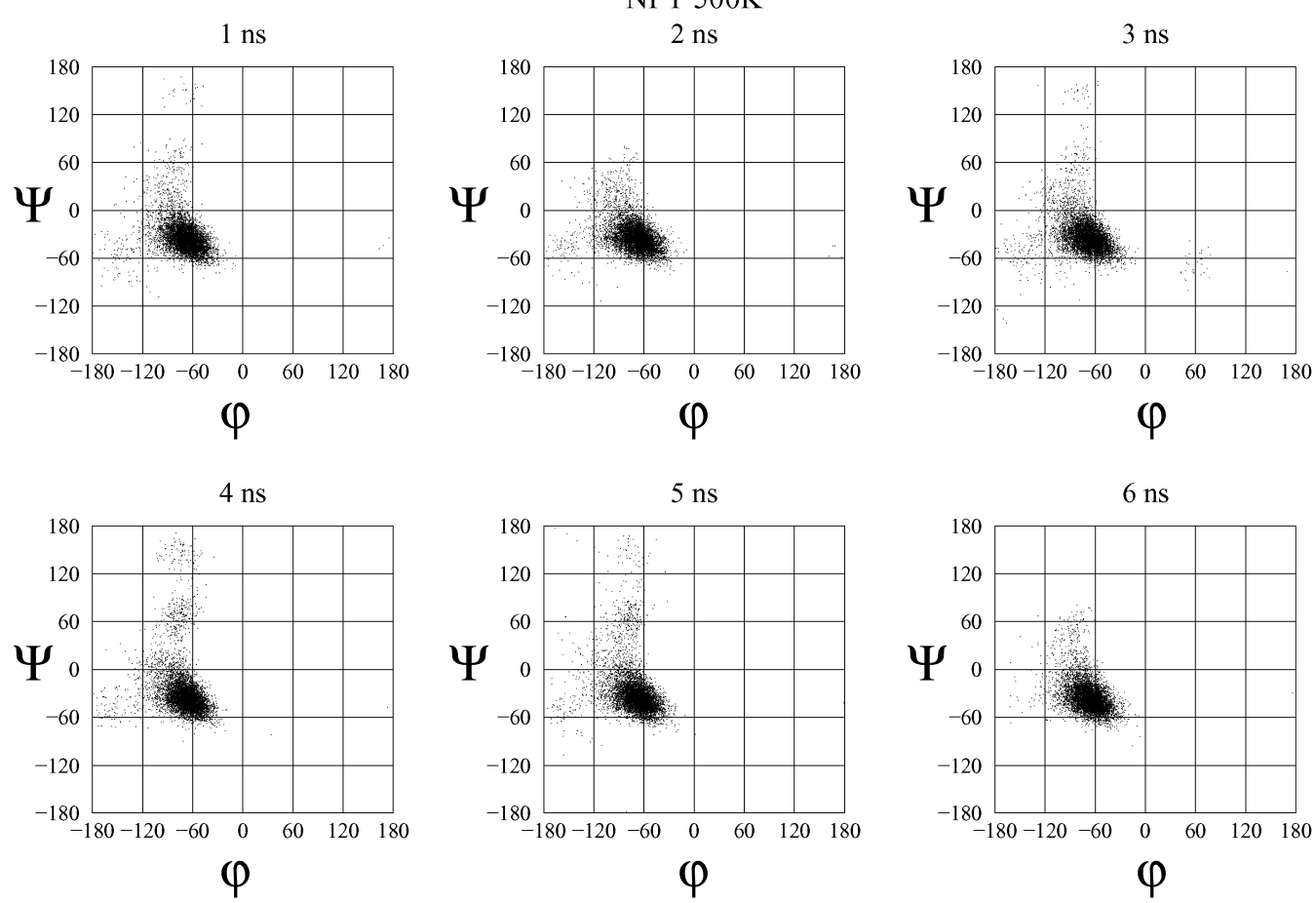